\title{
34. MELITÓN ATIENZA (1827-1890) Y SUS PROYECTOS DE JARDÍN 'GEOGRÁFICO' (MADRID, 1856) Y JARDÍN 'BOTÁNICO-ZOOLÓGICO DE ACLIMATACIÓN’ (MÁLAGA, 1878-1882).
}

\author{
Juan PÉREZ-RUBÍN
}

Melitón Atienza y Sirvent (Villaviciosa de Odón, Madrid, 1827 - Málaga, 1890) era hijo del navarro Mateo Atienza, jardinero del Real Jardín Botánico desde $1817^{1}$, y de la murciana María Sirvent ${ }^{2}$.

Tras terminar la carrera de Veterinaria siguió unos cursos de especialización en jardinería impartidos en el Real Jardín madrileño, probablemente en su Escuela Práctica de Alumnos Jardineros. En el mes de mayo de 1856 presentó, ante el Gobierno, una documentada memoria, acompañada con diferentes escritos y planos, en la que proponía grandes reformas en el propio Real Jardín y en su cercana Huerta de San Jerónimo, así como en los Jardines del Retiro y en "la montaña del Príncipe Pío o la Moncloa". Para el Jardín Botánico madrileño propuso el establecimiento de una Escuela de Horticultura y Arquitectura de Jardines, con un ambicioso plan de enseñanzas para la misma, y para las restantes zonas verdes un "Jardín Geográfico, que representase a España en las principales poblaciones, cordilleras, ríos y producciones naturales"3. Tres años después, Miguel Colmeiro Penido (1816-1901), a la sazón "director académico" del Real Jardín, elabora un informe para la dirección del Museo Nacional de Ciencias Naturales, en el que pone de manifiesto la inviabilidad técnica de dicho proyecto y la insuficiente preparación práctica del autor del mismo para llevarlo a cabo ${ }^{4}$.

M. Atienza finaliza sus estudios de Agronomía en Madrid y ejerce su nueva titulación en Alicante y Albacete. En 1877 toma posesión de la plaza de catedrático de Agricultura en el Instituto Provincial de Málaga. Con fecha de 20 de abril de 1878 presenta un ambicioso proyecto para crear en la ciudad un gran jardín botánico, que estaría agregado a su cátedra. Para darlo a conocer al público y buscar apoyo económico, publicó la memoria bajo el título: Breves consideraciones acerca del establecimiento de un jardín de Aclimatación de plantas intertropicales en los alrededores de Málaga (1879). El jardín por él propuesto tendría "un carácter científico y a la vez especulativo y de aplicación, para ensayar y estudiar las diversas maneras y mejores métodos de conseguir la producción de las plantas". Enumeraba el autor cerca de 150 especies diferentes de plantas aclimatables, explicaba su propuesta de estructura científica para el establecimiento (Arboreto y tres Escuelas: agronómica, de plantas medicinales y de floricultura) y, finalmente, proponía los medios económicos y administrativos necesarios para la fundación y mantenimiento del conjunto.

A pesar del total apoyo inicial de la Administración Local a sus propuestas, éstas no tuvieron éxito, el avance destructivo de la filoxera y sus negativas consecuencias económicas colaboraron a ello, el proyecto de jardín botánico malagueño había caído en el olvido a comienzos de 1881. En mayo de ese mismo año, Atienza ostenta el cargo municipal de "director de paseos y alamedas" de la capital, y vuelve a presentar un mejorado proyecto de jardín de aclimatación a la nueva Corporación del Ayuntamiento de Málaga. El 17 de mayo de 1881 la Corporación municipal acepta la idea con entusiasmo.

Comienza entonces el acondicionamiento de los terrenos; ante las primeras dificultades económicas, en septiembre de 1881, Atienza envía una memoria de su proyecto al Ministerio de Fomento y solicita su colaboración en el mismo. No debió recibir contestación y, al cabo de unos meses, el 26 de enero de 1883, remite un nuevo 
expediente en el que informaba sobre los avances conseguidos en el jardín de San Lázaro, donde "se han instalado los semilleros y viveros para la multiplicación artificial y forzada de los vegetales exóticos, contando con cajoneras de diversa forma y tamaño, acristaladas y sin acristalar". Con la nueva documentación aportada, Atienza amplía el proyecto original y solicita "semillas y algunos recursos", así como el patrocinio del Ministerio para "ampliarse y constituir un jardín zoólogoagrícola de aclimatación". A éste se importarían aquellos animales exóticos "que más inmediatamente pueden tener diversas aplicaciones a la agricultura y a las industrias rurales"s.

Consta el interés de la Corona por el proyecto pues, desde el Ministerio de Fomento y por decisión personal de S. M. el Rey, se solicita informe de viabilidad al Presidente del Consejo Superior de Agricultura, Industria y Comercio ${ }^{6}$. Éste, a su vez, envía copia para su valoración técnica a M. P. Graells, miembro destacado de "la Comisión especial encargada de formular dictamen acerca del establecimiento de Jardines de Aclimatación"?

Durante la tramitación de ese expediente, y de forma extraoficial, Atienza escribió una carta personal a Graells. Le pregunta, confidencialmente y en tono amistoso, sobre si su expediente ya había pasado al Consejo de Agricultura para su dictamen. Añadía: "He leído en los periódicos que se trata de establecer un jardín zoológico en Sevilla. ¿Es esto cierto?, ¿será que la segunda parte de mi exposición le haya agradado más al primer Ministro llevársela a su país?. También he sabido que en Madrid se trataba de fundar un jardín de aclimatación en el Retiro (...)"

\section{Notas}

1.El 5-III-1817, en un oficio dirigido a M. Lagasca (Presidente de la junta directiva del Real Jardín Botánico) se le comunica la Real Orden en la que consta el nombramiento de Mateo Atienza como nuevo jardinero (Arch. R.J.B., leg. $\mathrm{I}, 26,1,3)$. Al mismo se le concedió un ascenso el 20-XI-1834 (Arch. R.J.B., leg. I,47,1,12).

2. Certificado de defunción expedido en el Registro Civil de Málaga (tomo 47, folio 443, sección 31). También consta que el finado era soltero y que falleció de "albuminaria" en su domicilio de la calle de la Victoria $\mathrm{n}^{\circ} 13$, a los 63 años de edad, el 8 de noviembre de 1890.

3. Información contenida en el borrador de un informe de catorce páginas firmado por Colmeiro (vide infra). Arch. M.N.C.N., "Fondo del Real Jardín Botánico. Inventario somero de los años 1775-1938", caja n ${ }^{\circ} 7$. No hemos localizado la memoria original de Atienza sobre sus proyectos botánicos en Madrid.

4. La opinión de Colmeiro sobre Atienza y su proyecto es claramente negativa: "El proponente no es conocido como horticultor, ni como arquitecto de jardines, ni tiene demostrado que haya adquirido la necesaria destreza en establecimiento alguno, público o particular. Algún folleto histórico sobre los progresos de la jardinería y algunos artículos de periódico nada prueban en materias prácticas, y por otra parte, no es así como se llega al profesorado (...). Pocas indicaciones serán suficientes para reconocer lo inadmisible del proyecto (...) y del cual supone [Atienza] haberse adoptado algunas ideas en el R. D. de 7/1/1857 y en el Reglamento consiguiente que hoy rige en el Museo de Ciencias Naturales". A renglón seguido consta, aunque tachado posteriormente en el original: "No es ciertamente la modestia lo que más resalta en cuantos quieren pasar por atrevidos reformadores". Arch. M.N.C.N, "Fondo del Real Jardín Botánico. Inventario somero de los años 1775-1938”, caja n 7 . El informe está fechado el 28-VI-1859.

5. Memoria original (4 folios de papel timbrado): "Melitón Atienza y Sirvent, catedrático de agricultura del Instituto de Málaga y director del Jardín de Aclimatación de dicha capital a V.E. [Ministro de Fomento]" (sello de entrada del 31-I-1882). Comenta Atienza que el Jardín se encontraba "en el principio de su instalación, sostenido por el Excmo. Ayuntamiento con los escasos recursos de que es dado disponer", motivo por el cual "necesita del valioso apoyo de ese Ministerio a fin de proporcionarle semillas y algunos recursos para llevar a cabo su definitivo planteamiento (...). Si tuviese la fortuna de ser patrocinado por V. E. podría muy bien ampliarse y constituir un jardín zoólogoagrícola de aclimatación". Entre los animales exóticos "que más inmediatamente pueden tener diversas aplicaciones a la agricultura y a las 
industrias rurales", incluye a diferentes mamíferos (camello, llama, antílopes, ñu, etc.) y aves (avestruz, ganso de Egipto, faisán de América, pato de la Carolina, etc.). Arch. M.N.C.N. "Fondo Graells-Apuntes científicos", caja 13 , expediente 26 , documento I.

6. Carta (1 folio) con membrete del Ministerio de Fomento-Agricultura, tramitando el expediente al marqués de Monistrol, presidente del citado Consejo. Arch. M.N.C.N., "Fondo GraellsApuntes científicos", caja 13, expediente 26, documento II. El escrito lleva fecha de 10-II1882.

7. Carta ( 1 folio) del marqués de Monistrol, con membrete del Consejo de Agricultura ("Sección $1^{\text {a }}$ Presidencia"), dirigida al "Excmo. Sr. D. Mariano de la Paz Graells". Arch. M.N.C.N., "Fondo Graells-Apuntes científicos", caja 13, expediente 26, documento III, el escrito lleva fecha de 2-VI-1882.

8. Comienza el escrito de Atienza a Graells: "Le remito esta carta con el fin de saber, sin pérdida de tiempo, si mi expediente ha pasado al Consejo y si está en poder de Ud. Cuando reciba contestación escribiré al $1^{\text {er }}$ director de Agricultura. Varios primeros de Málaga me han preguntado por las semillas de vides americanas y he hablado con su sobrino, que me ha dicho haberle escrito...". Arch. M.N.C.N., "Fondo del RJB. Inventario somero de los años 1775-1938", caja n 7 , expediente de la "Asociación de Agricultura de España, etc.". Aunque no está fechado, es posible que el escrito fuera remitido el 1-III-1882.

Dirección del autor: Juan PÉREZ-RUBíN. Centro Oceanográfico de Málaga. Instituto Español de Oceanografía. Muelle Pesquero s/n. 29640 Fuengirola (Málaga).

\title{
35. LAS RELACIONES DE MARIANO DE LA PAZ GRAELLS (1809-1898) CON LA ACADEMIA DE CIENCIAS NATURALES Y FÍSICAS DE MÁLAGA EN 1841.
}

\author{
Juan PÉREZ-RUBÍN
}

Según cuatro cartas custodiadas en el Museo Nacional de Ciencias Naturales (MNCN, Fondo Graells-Caja n 1: "Exped. 5/Caja 1"), las primeras relaciones de Graells con Málaga parecen remontarse al mes de abril de 1841. A la sazón tenía 32 años de edad y, desde 1837, era catedrático de Zoología en el MNCN y miembro de la Real Academia de Ciencias de Madrid.

En dicho año 1841 recibe Graells dos cartas de la Academia de Ciencias Naturales y Físicas de Málaga (ACNFM). En la primera misiva, sin fecha, el secretario de gobierno de la ACFNM
(Eduardo Gilly), le notifica su nombramiento de académico correspondiente, confiando en "que contribuirá a la propagación y adelantos de las ciencias [naturales]", y corresponderá "acompañando las tareas que se pongan a su cuidado". En la segunda carta de la ACFNM (20/ 4/1841, dirigida a la c/del León, 13; Madrid), firmada por A. J. Velasco ('secretario de correspondencia’?), se le pregunta a cual sección desea pertenecer (Ciencias Naturales o Físicas) y a que rama de la investigación "se dedica particularmente". 